\title{
HORIZONTAL POSITIONAL ACCURACY OF GOOGLE EARTH'S IMAGERY OVER RURAL AREAS: A STUDY CASE IN TAMAULIPAS, MEXICO
}

Exactitud posicional horizontal de las imágenes de Google Earth en áreas rurales: Un caso de estudio en Tamaulipas, México.

\author{
CUTBERTO URIEL PAREDES-HERNÁNDEZ ${ }^{1}$ \\ WILVER ENRIQUE SALINAS-CASTILLO ${ }^{1}$ \\ FRANCISCO GUEVARA-CORTINA ${ }^{2}$ \\ XICOTÉNCATL MARTÍNEZ-BECERRA ${ }^{2}$ \\ ${ }^{1}$ Unidad de Geomática, Instituto de Ingeniería y Ciencias, \\ Universidad Autónoma de Tamaulipas, México \\ ${ }^{2}$ GeoExpert S.C., México \\ cparedes@uat.edu.mx
}

\begin{abstract}
Due to the popularity of Google Earth (GE), users commonly assume that it is a credible and accurate source of information. Consequently, GE's imagery is frequently used in scientific and others projects. However, Google states that data available in their geographic products are only approximations and, therefore, their accuracy is not officially documented. In this paper, the horizontal positional accuracy of GE's imagery is assessed by means of comparing coordinates extracted from a rural cadastral database against coordinates extracted from well-defined and inferred check points in GE's imagery. The results suggest that if a large number of well-defined points are extracted from areas of high resolution imagery, GE's imagery over rural areas meets the horizontal accuracy requirements of the ASPRS for the production of "Class 1" 1:20,000 maps. Nonetheless, the results also show that georegistration and large horizontal errors occur in GE's imagery. Consequently, despite its overall horizontal positional accuracy, coordinates extracted from GE's imagery should be used with caution.
\end{abstract}

Keywords: Google Earth; Horizontal Positional Accuracy; Horizontal RMSE; CE95 


\section{RESUMEN}

Debido a la popularidad de Google Earth (GE), los usuarios asumen que es una fuente de información creíble y exacta. En consecuencia, imágenes de GE son frecuentemente utilizadas en proyectos científicos y de otras índoles. Sin embargo, Google especifica que los datos disponibles en sus productos geográficos son solo aproximaciones y, por lo tanto, la precisión de dichos productos no es documentada oficialmente. En este artículo, la exactitud posicional horizontal de las imágenes de GE se evalúa por medio de la comparación de coordenadas extraídas de una base de datos catastral rural contra coordenadas extraídas de puntos de verificación bien definidos e inferidos en las imágenes de GE. Los resultados sugieren que si se extrae un gran número de puntos bien definidos de áreas con imágenes de alta resolución, las imágenes de GE en áreas rurales cumplen con los requisitos de exactitud horizontal de la ASPRS para la producción de mapas 1:20,000 de "Clase 1". No obstante, los resultados también muestran que existen errores de georeferenciación y otros errores horizontales grandes en las imágenes de GE. Por consiguiente, a pesar de la exactitud posicional horizontal de GE, coordenadas extraídas de imágenes de GE deben ser usadas con precaución.

Palabras clave: Google Earth; Exactitud Posicional Horizontal; EMC Horizontal; CE95

\section{INTRODUCTION}

Google Earth (GE) is the most popular virtual globe that offers free access to high resolution imagery for most of the planet. Since the launch of the program in 2005 by Google, it has been downloaded more than 1 billion times to desktop and mobile clients (GOOGLE, 2011). Unfortunately, given the popularity of GE, users tend to assume that it is an accurate source of information and also tend not to question its credibility (FLANAGIN; METZGER, 2008). Also, the practice of GE of reporting coordinates with a precision that does not match its accuracy misleads users to believe that it is an accurate source of information (GOODCHILD et al., 2012). Moreover, Benker, Langford and Pavlis (2011) note that Google representatives state that the coordinates provided by Google are approximations only and that, therefore, Google makes no claims as to the accuracy of their geographic information products (GOOGLE, 2008, 2009). However, in 2008, Google initiated a project called "Ground Truth" in order to increase the accuracy of their geographic products by means of acquiring data from authoritative sources (GOOGLE, 2012) such as INEGI (the Mexican National Institute for Geography and Statistics) and NGA (the USA National Geospatial-Intelligence Agency).

As a result of its popularity, GE is commonly used by the scientific community in their projects. GE has been used, for example, to collect ground control points (GCPs) for orthorectification of satellite imagery (YOUSEFZADEH; MOJARADI, 2012), to estimate urban vegetation cover (DUHL; GUENTHER; HELMIG, 2012), to visualize the output of scientific experiments (WHEATON et al., 2012; 
PERISSIN; WANG; LIN, 2012), to map landslides (PERUCCACCI et al., 2012) and as reference data to evaluate land cover datasets (CHA; PARK, 2007; NOWAK; GREENFIELD, 2010), among other applications. In most of the scientific applications listed above, the authors of the papers have exercised some caution with regards to the accuracy of GE. Therefore, in order to understand and reduce the uncertainties associated with the use of GE in different applications, accuracy assessments of GE's imagery are required (POTERE, 2008; YU; GONG, 2012).

Consequently, a series of accuracy assessments of GE's imagery have been undertaken by different researchers. Potere (2008) evaluated the horizontal positional accuracy of GE's imagery using control points extracted from the Landsat GeoCover dataset and estimated a global horizontal root mean squared error $\left(\mathrm{RMSE}_{\mathrm{r}}\right)$ of $39.7 \mathrm{~m}$. However, the horizontal accuracy of Landsat GeoCover, about $50 \mathrm{~m} \mathrm{RMSE}_{\mathrm{r}}$ (TUCKER; GRANT; DYKSTRA, 2004), is larger than the accuracy estimated for GE. Therefore, the results should be interpreted conservatively due to the uncertainty introduced by the dataset used as reference (POTERE, 2008). In a similar global study, Becek and Ibrahim (2011) estimated GE's global horizontal mean error in $113 \mathrm{~m}$, with errors in the range from 10 to $1,500 \mathrm{~m}$, using as reference runways compiled from multiples sources. Unfortunately, since Becek and Ibrahim (2011) do not state the estimated accuracy of the dataset they used in their study, their results should also be handled with caution.

Regarding regional studies, Benker, Langford and Pavlis (2011) used highprecision field measurements $(<1 \mathrm{~m})$ to assess the accuracy of GE' imagery in the Big Bend region of Texas, USA and found that GE's imagery has a horizontal mean error of $6.95 \mathrm{~m}$ and $\mathrm{RMSE}_{\mathrm{r}}$ of $2.64 \mathrm{~m}$. However, their methodology (square root of the mean error) to calculate $\mathrm{RMSE}_{\mathrm{r}}$ differs from that defined in authoritative documents such as the Geospatial Positioning Accuracy Standards of the Federal Geographic Data Committee of the USA (FGDC, 1998). Therefore, the RMSE estimated for GE by Benker, Langford and Pavlis (2011) should be regarded only as a statistic relevant to their study and not as a valid accuracy assessment of GE (SALINAS-CASTILLO; PAREDES-HERNANDEZ, 2013). In another regional study, Yousefzadeh and Mojaradi (2012) estimated GE's horizontal accuracy in 6.1 $\mathrm{m} \mathrm{RMSE}_{\mathrm{r}}$, with a mean horizontal error of $4.8 \mathrm{~m}$, using 13 check points (CPs) collected from 1:2,000-scale maps and distributed over a study area of approximately $215 \mathrm{~km}$ in width located in southern Iran. However, their results may not be representative of GE's horizontal accuracy due to the limited number of CPs they used.

Therefore, in this paper we attempt to contribute to the understanding of the horizontal positional accuracy of GE's imagery by means of a study case undertaken over rural areas, using accurate field and photogrammetric measurements as reference data and addressing some of the issues identified in previous studies. In the following sections we describe the datasets used in this study and the methodology used to assess the horizontal accuracy of GE's imagery, present the 
results of the study case and, finally, draw a series of conclusions from the results of this and other studies.

\section{DATASETS AND METHODOLOGY}

In this study, the horizontal positional accuracy of GE's imagery is assessed using as reference 466 parcel vertices (Figure 1) extracted from a rural cadastral survey undertaken by the Mexican National Institute for Geography and Statistics (INEGI, 2013). The vertices were extracted from fenced grazing parcels located on flat terrain in Tamaulipas, Mexico. The description of both datasets GE's imagery and the parcels survey by INEGI is presented in the following two subsections.

Figure 1 - Study area and the location of 466 check points (CPs) used to assess the horizontal positional accuracy of GE's imagery.

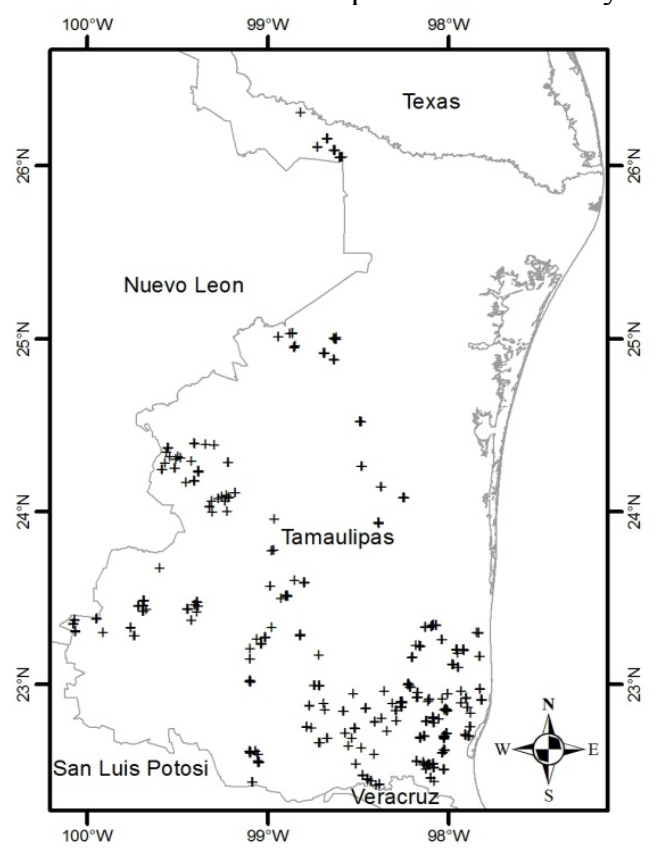

Study Area
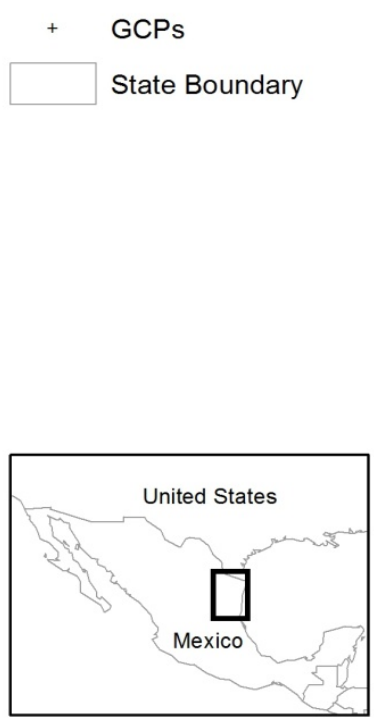

\subsection{Google Earth's Imagery}

GE's imagery is compiled from a variety of sources that include both commercial and public data providers (GOOGLE, 2013a). Therefore, the spatial resolution of GE's imagery is not uniform and areas of high, medium and low resolution coexist. The provider of most of the high resolution imagery (pixel size of less than $1 \mathrm{~m}$ ) for GE is Digital Globe (DG) (POTERE, 2008), a company that owns QuickBird and WorldView-1 and 2. Digital Globe (2013) claims that 
Quickbird imagery has a circular error at the $90 \%$ confidence interval (CE90) of 23 $\mathrm{m}$ and that WorldView- 1 and 2 have a CE90 of $5 \mathrm{~m}$. For the area covered by this study, some of GE's imagery is acquired using CNES' SPOT5, which has a CE90 of $50 \mathrm{~m}$ without ground control points (GCPs) (CNES, 2013). Google does not document the level of processing (e.g. geometric correction, orthorectification) applied to any of these data sources before adding them to GE.

Since major changes are likely to occur seasonally in agricultural fields and in order to reduce errors introduced by changing conditions between data and reference data collection, only vertices from fenced grazing parcels were selected as $\mathrm{CPs}$, where changes are less prone to occur due to the cost of relocating fences. Furthermore, in areas where high resolution imagery was available in GE, only those vertices that where either visible (well-defined points; Figure 2) or could be inferred from fences (Figure 3) were selected as CPs. In areas of medium resolution, grazing fields were also used but the location of the vertices was inferred visually based on changes in land cover. A total of 466 vertices (Figure 1) were visually identified as suitable to be used as CPs. The $\mathrm{x}, \mathrm{y}$ coordinates (or Easting and Northing, respectively) of these vertices were extracted manually from GE, which was set up to display coordinates using the Universal Transverse Mercator (UTM) coordinate system with a WGS84 datum (GOOGLE, 2013b). All coordinates extracted from GE fall within the UTM Zone 14 coordinate range.

Figure 2 - Visible vertex of a fenced grazing parcel used as a well-defined check point. The center coordinates of the figure are $24.106036^{\circ} \mathrm{N}, 99.177950^{\circ} \mathrm{W}$. (C) 2013 Google. (C) 2013 DigitalGlobe.

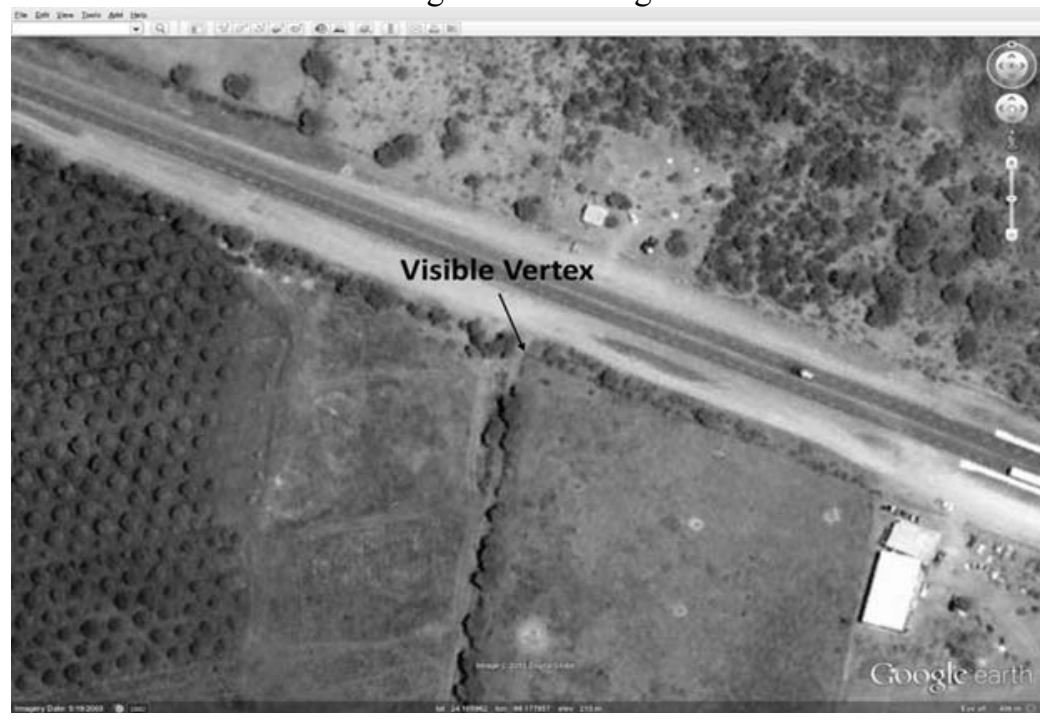


Figure 3 - The location of the parcel vertex obscured by trees was inferred from nearby fences and used as a check point. The center coordinates of the figure are $22.690971^{\circ} \mathrm{N}, 98.022363^{\circ} \mathrm{W}$. (C) 2013 Google. (C) 2013 DigitalGlobe.

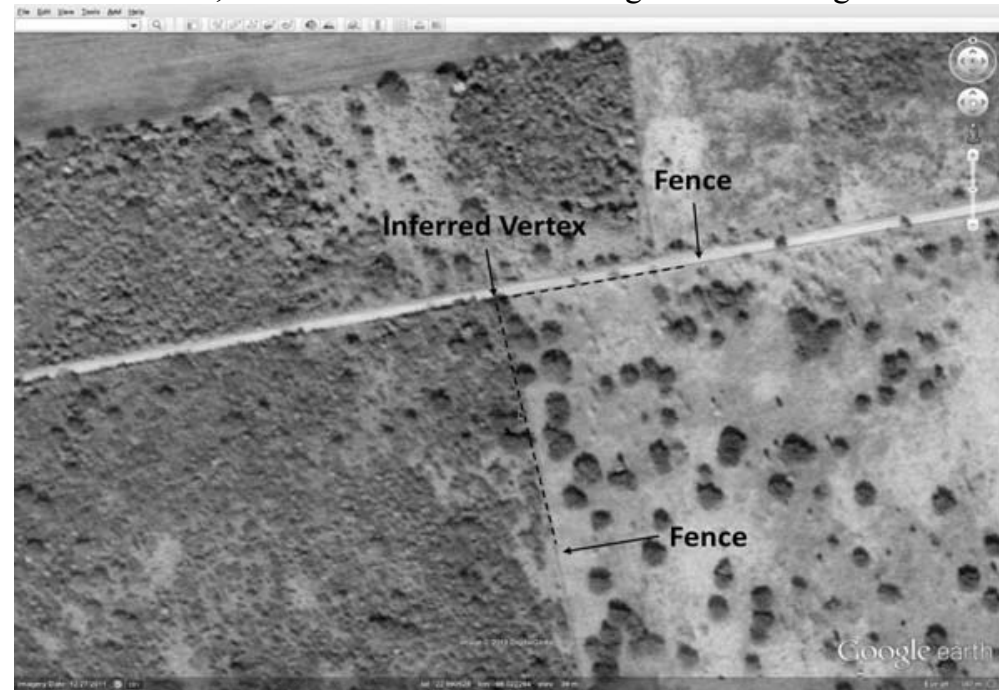

\subsection{INEGI Parcels (reference dataset)}

The dataset used as reference in this study was extracted from a cadastral survey of the rural social property in Mexico undertaken by INEGI (2013) using both field measurements and photogrammetric techniques. Field measurements were collected using dual-band GPS and topographic total stations with an accuracy of less than $1 \mathrm{~m} \mathrm{RMSE}$. Photogrammetric measurements were collected from high resolution aerial orthophotos with maximum horizontal errors of $2 \mathrm{~m}$ (RAN, 1995). For this study, the parcels dataset was accessed through INEGI's web map service (WMS) and the coordinates (x,y) of the parcel vertices selected as CPs in GE were extracted manually. The coordinates from the reference dataset were also extracted in the UTM coordinate system with a WGS84 datum in order to be able to compare the coordinates of both data sources without the need of coordinate system transformations.

\subsection{Accuracy Assessment (Methodology)}

Once the coordinates of the CPs were extracted from both datasets, GE's imagery horizontal positional accuracy was assessed in terms of $\mathrm{x}, \mathrm{y}$ and horizontal root mean squared error $\left(\mathrm{RMSE}_{\mathrm{x}}, \mathrm{RMSE}_{\mathrm{y}}\right.$ and $\mathrm{RMSE}$, respectively) (equations taken from FGDC (1998)): 


$$
\begin{gathered}
R M S E_{x}=\sqrt{\frac{\sum_{i}\left(x_{\text {data }, i}-x_{\text {reference }, i}\right)^{2}}{n}} \\
R M S E_{y}=\sqrt{\frac{\sum_{i}\left(y_{\text {data }, i}-y_{\text {reference }, i}\right)^{2}}{n}} \\
R M S E_{r}=\sqrt{R M S E_{x}^{2}+R M S E_{y}^{2}}
\end{gathered}
$$

where: $\quad x_{\text {data }, i}, y_{\text {data }, i}$ are the coordinates of the $i^{\text {th }}$ point in the evaluated dataset,

$x_{\text {reference, },}, y_{\text {reference, } i}$ are the coordinates of the $i^{\text {th }}$ point in the independent reference dataset of higher accuracy,

$n$ is the number of CPs, and

$i$ is an integer that ranges from 1 to $n$.

Horizontal accuracy at the 95\% confidence level (CE95) was computed for both anisotropic and non-anisotropic accuracies. For anisotropic accuracies, where $\mathrm{RMSE}_{\mathrm{x}} \neq \mathrm{RMSE}_{\mathrm{y}}$ and the proportion between $\mathrm{RMSE}_{\min }$ and $\mathrm{RMSE}_{\text {max }}$ is between 0.6 and 1.0, CE95 was computed as (FGDC, 1998):

$$
C E 95 \sim 1.2238 *\left(R M S E_{x}+R M S E_{y}\right)
$$

For non-anisotropic accuracies, where $\mathrm{RMSE}_{\mathrm{x}}=\mathrm{RMSE}_{\mathrm{y}}, \mathrm{CE} 95$ was computed as (Ibid.):

$$
C E 95=1.7308 * R M S E_{r}
$$

Mean horizontal error and error standard deviation were calculated from the set of individual horizontal errors:

$$
\sqrt{\left(x_{\text {data }, i}-x_{\text {reference }, i}\right)^{2}-\left(y_{\text {data }, i}-y_{\text {reference }, i}\right)^{2}}
$$

$\mathrm{RMSE}_{\mathrm{r}}, \mathrm{RMSE}_{\mathrm{x}}, \mathrm{RMSE}_{\mathrm{y}}, \mathrm{CE} 95$, mean horizontal error and horizontal error standard deviation were computed for the full CP dataset and for relevant CP subsets such as medium and high resolution, inferred and not inferred CPs from high resolution imagery, and collected from imagery taken before and after 2008. The results of these accuracy assessments are presented in the next section. 


\section{RESULTS}

During the collection of CPs from GE, large georegistration errors (Figure 4) were identified in GE's imagery. Georegistration errors are easily identified visually from disjoint linear features such as roads and parcel boundaries (POTERE, 2008). Unfortunately, these errors are inherited by all locations captured by misregistered images and, moreover, when new imagery is added, the location of features extracted from misregistered images "will be offset by any positional difference in the new registration" (GOODCHILD et al., 2012, p. 11089). Consequently, in areas nearby, the scientific utility of GE's imagery archive is limited by these errors (POTERE, 2008) and coordinates extracted from these areas should only be used as approximations and not as ground truth.

Figure 4 - Georegistration error in Google Earth's imagery. All locations extracted from this area inherit the error introduced by misregistration. The center coordinates of the figure are $22.543894^{\circ} \mathrm{N}, 98.181197^{\circ} \mathrm{W}$. (C) 2013 Google. (C) 2013 DigitalGlobe.

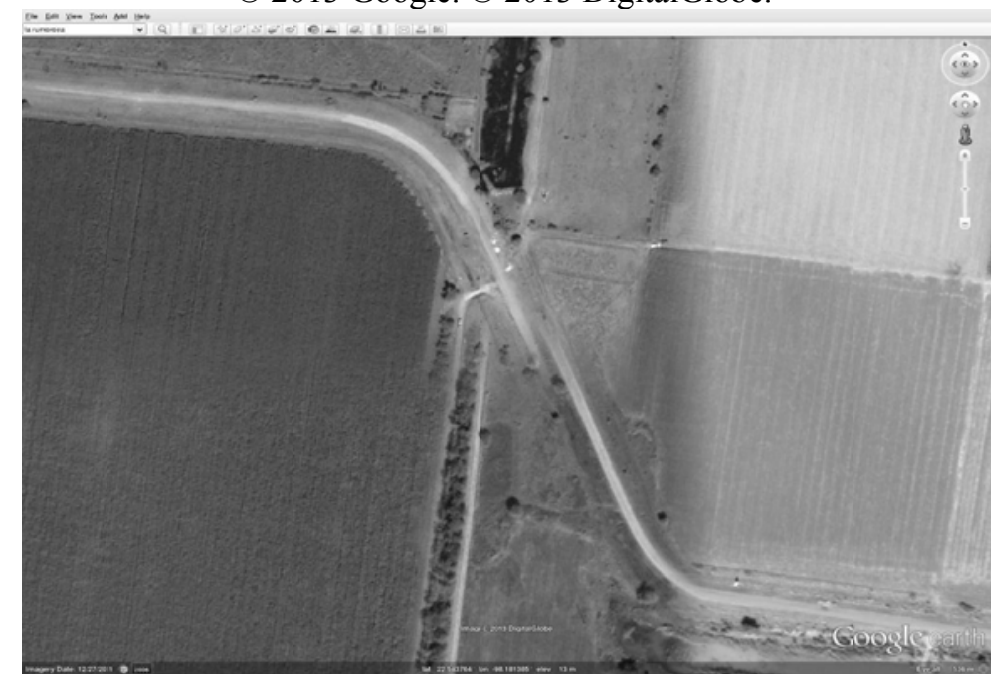

Nevertheless, the results of the horizontal accuracy assessment of the entire set of CPs and of relevant subsets (Tables 1 and 2) show that the impact of georegistration errors is reduced in the overall statistics by the presence of other accurate locations. If the accuracy is evaluated using all CPs, regardless of their collection method and data provider, GE's imagery horizontal positional accuracy over rural areas is $5.0 \mathrm{~m} \mathrm{RMSE}_{\mathrm{r}}$ (Equation 3), with mean horizontal error of $4.1 \mathrm{~m}$ and standard deviation (SD) of $2.9 \mathrm{~m}$ (Table 1). Therefore, the horizontal accuracy of GE's imagery over these areas at the $95 \%$ confidence level (CE95) is $8.6 \mathrm{~m}$ (Equation 4). A horizontal accuracy that surpasses the accuracy stated by GE's data 
providers (CNES, 2013; DIGITAL GLOBE; 2013). Since Google is reluctant to document the accuracy of their geographic products, it can only be assumed that this is the result of the Ground Truth program of Google (2012). Unfortunately, even when the overall horizontal accuracy is better than expected, large horizontal errors of up to $20.9 \mathrm{~m}$ exist in the full dataset of CPs (Table 2).

However, it should be noted that larger horizontal errors are observed in CPs collected over areas where only medium resolution (SPOT) imagery is available in GE (Table 2); possibly due to a less accurate location of CPs on coarser resolutions. Therefore, accuracy assessments were undertaken separately for subsets of CPs collected over areas of medium (SPOT) and high (DG) resolution imagery. Using $52 \mathrm{CPs}$ collected from SPOT imagery, GE's imagery horizontal accuracy over rural areas of medium resolution was calculated in 7.6 m RMSE $_{\mathrm{r}}$ (mean: $6.4 \mathrm{~m}$; SD: 4.0 $\mathrm{m}$ ) and $12.8 \mathrm{~m}$ CE95. The distribution of the error vectors of these $52 \mathrm{CPs}$ (Figure 5a), shows that the $x$-component of horizontal errors is significantly larger than the $\mathrm{y}$-component in GE's imagery over these areas of medium resolution $\left(\mathrm{RMSE}_{\mathrm{x}}\right.$ : 6.4; $\mathrm{RMSE}_{\mathrm{y}}$ : 4.0; Table1); and indicates a horizontal offset towards east in GE's medium resolution imagery possibly caused by the presence of uncorrected imagery acquired using large off-nadir angles. Yet, even when larger errors occur over these areas and systematic errors are present, the horizontal positional accuracy of GE's medium resolution imagery is better than that specified by the data provider when no GCPs are used to georeference its imagery (CNES, 2013).

Over areas of high resolution in GE, the results show that the horizontal accuracy estimated using inferred CPs (DG Inf) is slightly lower than the accuracy estimated using only well-defined CPs (DG Vis) (Tables 1 and 2). However, since the difference is not statistically significant at the $1 \%$ level of significance (t-test), inferred CPs can be considered as valid as well-defined CPs in this study. Therefore, GE's imagery horizontal accuracy over areas of high resolution was assessed using all CPs collected over areas of high resolution, regardless of their collection method. Using 414 CPs (DG) collected over rural areas, the positional horizontal accuracy of GE's high resolution imagery was estimated in $4.5 \mathrm{~m} \mathrm{RMSE}_{\mathrm{r}}$ (mean: $3.8 \mathrm{~m}$; SD: 2.5 $\mathrm{m}$ ) and $7.8 \mathrm{~m}$ CE 95 (Table 1) with horizontal errors of up to $16.5 \mathrm{~m}$ (Table 2). The distribution of error vectors over these areas (Figure 5b) shows that error vector orientations are randomly distributed. Likewise, the difference between $\mathrm{RMSE}_{\mathrm{x}}$ and RMSE $_{\mathrm{y}}$ (Table 1) is not significant. Therefore, systematic errors are not apparent in GE's high resolution imagery available in rural areas.

In order to verify the inferred effects of Google's "Ground Truth" program (GOOGLE, 2012) on the horizontal positional accuracy of GE's imagery, separate accuracy assessments were undertaken for CPs extracted from GE's imagery collected before $(\mathrm{DG}<2008)$ and from 2008 onwards $(\mathrm{DG}>=2008)$. Unfortunately, since imagery date is only available for high resolution areas in GE, this accuracy assessment was undertaken using only CPs collected from high resolution imagery. The horizontal positional accuracy of GE's pre-2008 rural imagery was estimated in $6.3 \mathrm{~m} \mathrm{RMSE}_{\mathrm{r}}$ (mean: $5.7 \mathrm{~m}$; SD: $2.7 \mathrm{~m}$ ) and $10.9 \mathrm{~m} \mathrm{CE} 95$ 
using 60 CPs extracted from imagery collected before 2008 (Table 1). Meanwhile, the horizontal positional accuracy for GE's high resolution rural imagery collected from 2008 onwards was estimated in $4.2 \mathrm{~m} \mathrm{RMSE}_{\mathrm{r}}$ (mean: $3.4 \mathrm{~m}$; SD: $2.3 \mathrm{~m}$ ) and $7.2 \mathrm{~m}$ CE95 using 354 CPs (Table 1). Regarding the presence of systematic errors, the distribution of error vectors for theses subsets (Figures $5 \mathrm{c}$ and $5 \mathrm{~d}$ ) suggest that while in imagery collected from 2008 onwards error vectors are randomly distributed, in imagery collected before 2008 a horizontal offset towards northwest may be present. Therefore, since the horizontal accuracy of pre-2008 imagery in GE is significantly lower than that of imagery collected during and after 2008 (tested at the $1 \%$ level of significance using t-test) and larger horizontal errors occur in pre2008 imagery (Table 2), the results suggest that, possibly as a result of the "Ground Truth" program, imagery added after 2008 to GE has a better horizontal positional accuracy than imagery added before 2008 .

Regarding the use of GE's imagery as a source of information for science and other projects, the results suggest that the overall horizontal accuracy of GE's imagery over rural areas fulfills the $5.0 \mathrm{~m} \mathrm{RMSE}_{\mathrm{r}}$ requirement of the ASPRS (1990) for the production of "Class 1" 1:20,000 maps. However, this requirement is only met if a large number of points are collected from features that can be clearly identified visually in high resolution imagery. If data for a project are extracted from both GE's medium and high resolution imagery, a larger number of well-defined points should be extracted from GE's high resolution imagery in order to reduce the effect of inaccuracies introduced by data extracted from medium resolution areas on accuracy statistics. Unfortunately, if only medium resolution imagery is available in GE for a rural area of interest, the results suggest that the horizontal accuracy requirement for "Class 1" 1:20,000 maps is not met. However, the accuracy of GE's medium resolution over these areas meets the ASPRS (1990) requirement for "Class 2"1:20,000 maps (maximum $\mathrm{RMSE}_{\mathrm{r}}$ of $10 \mathrm{~m}$ ).

Table 1 - Horizontal positional accuracy of GE's imagery. SD = Standard deviation. Units: meters.

\begin{tabular}{c|c|c|c|c|c|c|c}
\hline Subset & CPs & RMSE $_{\mathrm{r}}$ & Mean & SD & RMSE $_{\mathrm{x}}$ & RMSE $_{\mathrm{y}}$ & CE95 \\
\hline GE & 466 & 5.0 & 4.1 & 2.9 & 3.8 & 3.2 & 8.6 \\
\hline SPOT & 52 & 7.6 & 6.4 & 4.0 & 6.4 & 4.0 & 12.8 \\
\hline DG & 414 & 4.5 & 3.8 & 2.5 & 3.3 & 3.1 & 7.8 \\
\hline DG Inf & 198 & 4.6 & 3.9 & 2.6 & 3.3 & 3.3 & 8.0 \\
\hline DG Vis & 216 & 4.4 & 3.7 & 2.5 & 3.4 & 2.9 & 7.7 \\
\hline DG $<2008$ & 60 & 6.3 & 5.7 & 2.7 & 4.2 & 4.8 & 10.9 \\
\hline DG $>=2008$ & 354 & 4.2 & 3.4 & 2.3 & 3.2 & 2.7 & 7.2 \\
\hline
\end{tabular}


Table 2 - Minimum and maximum horizontal error and $\mathrm{x}$ and y error components in GE's imagery. Units: meters.

\begin{tabular}{c|c|c|c|c|c|c|c}
\hline Subset & CPs & $\operatorname{Min}_{\mathrm{r}}$ & $\operatorname{Max}_{\mathrm{r}}$ & $\operatorname{Min}_{\mathrm{x}}$ & $\operatorname{Max}_{\mathrm{x}}$ & $\operatorname{Min}_{\mathrm{y}}$ & $\operatorname{Max}_{\mathrm{y}}$ \\
\hline GE & 466 & 0.1 & 20.9 & -16.4 & 19.8 & -12.5 & 10.5 \\
\hline SPOT & 52 & 0.2 & 20.9 & -7.2 & 19.8 & -12.5 & 6.8 \\
\hline DG & 414 & 0.1 & 16.5 & -16.4 & 11.3 & -10.4 & 10.5 \\
\hline DG Inf & 198 & 0.1 & 12.5 & -9.5 & 11.3 & -8.4 & 9.2 \\
\hline DG Vis & 216 & 0.2 & 16.5 & -16.4 & 10.8 & -10.4 & 10.5 \\
\hline DG $<2008$ & 60 & 0.2 & 16.5 & -16.4 & 8.0 & -7.2 & 10.5 \\
\hline DG $>=2008$ & 354 & 0.1 & 13.4 & -9.5 & 11.3 & -10.4 & 9.2 \\
\hline
\end{tabular}

\section{CONCLUSIONS}

A series of independent horizontal accuracy assessments have been undertaken at both global and regional scales. At the global scale, accuracy assessments have been undertaken using as reference datasets of low (POTERE, 2008) or undocumented (BECEK; IBRAHIM, 2011) horizontal accuracy. Consequently, the results of these accuracy assessments should be interpreted with some caution. At regional scales, high accuracy field measurements (BENKER, LANGFORD; PAVLIS, 2011) or large scale maps (YOUSEFZADEH, MOJARADI, 2012) have been used as reference to assess the horizontal accuracy of GE's imagery. The results of these studies suggest that the horizontal positional accuracy of GE's imagery is better than that estimated in studies at the global scale, possibly due to the use of more accurate reference datasets.

The results presented in this paper are consistent with this latter finding. Using accurate field and photogrammetric measurements (extracted from a cadastral database) as the reference dataset and comparing them against well-defined and inferred locations (CPs) in GE's medium and high resolution imagery, the estimated horizontal positional accuracy of GE's imagery over rural areas (5.0 m RMSEr) was found to meet the horizontal accuracy requirements of the ASPRS (1990) for the production of "Class 1" 1:20,000 maps. However, the results also suggest that this accuracy requirement might not be met for rural areas if coordinates are extracted only from GE's medium resolution imagery or from imagery collected before 2008 . Furthermore, despite the results presented here, GE's imagery should be used with caution due to the presence of large georegistration errors in both GE's medium and high resolution imagery. 
Figure 5 - GE's imagery horizontal error vectors for (a) 52 SPOT, (b) 414 DG, (c) 60 DG pre 2008 and (d) 354 DG post 2008 check points. Units: meters. North: $0^{\circ}$.

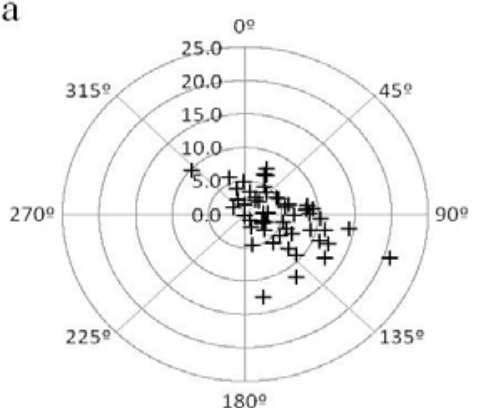

$\mathrm{c}$

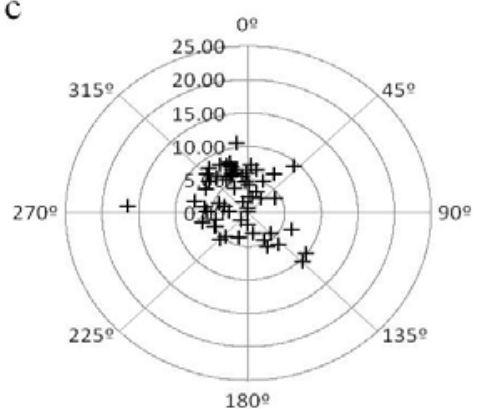

b

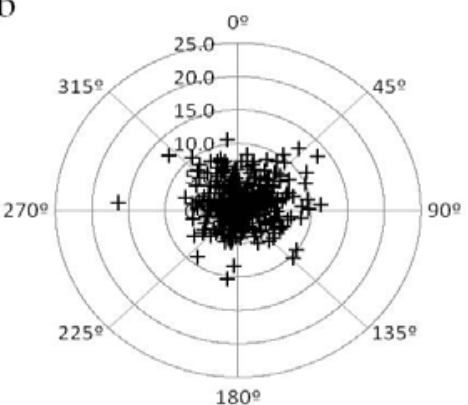

d

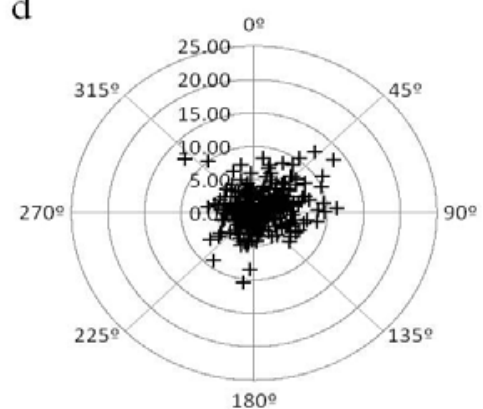

\section{ACKNOWLEDGEMENTS}

The authors would like to thank Nora E. Macias-Pérez from INEGI for her orientation on the geographic information products freely available at INEGI. The authors are also very thankful to two anonymous reviewers whose comments greatly enhanced the original manuscript. Any remaining mistakes remain our sole responsibility.

\section{REFERENCES}

ASPRS. AMERICAN SOCIETY FOR PHOTOGRAMMETRY AND REMOTE SENSING. ASPRS accuracy standards for large-scale maps. Photogrammetric Engineering \& Remote Sensing, 56(7), 1068-1070, 1990.

BECEK, K.; IBRAHIM, K. On the positional accuracy of the Googleearth ${ }^{\circledR}$ imagery. TS05I - Spatial Information Processing Ipaper no. 4947. In: FIG Working Week 2011, Marrakech, Morocco, 18-22 May 2011. 
BENKER, S.C; LANGFORD, R.P.; PAVLIS, T.L. Positional accuracy of the Google Earth terrain model derived from stratigraphic unconformities in the Big Bend region, Texas, USA. Geocarto International, 26(4), 291-301, 2011.

CHA, S.; PARK, C. The utilization of Google Earth images as reference data for the multitemporal land cover classification with MODIS data of North Korea. Korean Journal of Remote Sensing, 23(5), 483-491, 2007.

CNES. CENTRE NATIONAL D’ÉTUDES SPATIALES (FRANCE). Un Système opérationnel et performant. Images. Available at: http://spot5.cnes.fr/systeme /systeme.htm. Accessed: 22 March 2013.

DIGITAL GLOBE. Basic Imagery Data Sheet. Available at: http://www. digitalglobe.com/downloads/BasicImagery-DS-BASIC-Web.pdf. Accessed: 20 March 2013.

DUHL, T.R.; GUENTHER, A.; HELMIG, D. Estimating urban vegetation cover fraction using Google Earth ${ }^{\circledR}$ images. Journal of Land Use Science, 7(3), 311329, 2012.

FGDC. FEDERAL GEOGRAPHIC DATA COMMITTEE (USA). Geospatial Positioning Accuracy Standards. Part 3: National Standard for Spatial Data Accuracy. Reston, Virginia, USA, 1998.

FLANAGIN, A.J; METZGER, M.J. The credibility of volunteered geographic information. GeoJournal, 72, 137-148, 2008.

GOODCHILD, M.F.; GUO, H.;ANNONI, A.; BIAN, L.; DE BIE, K.; CAMPBELL, F.; CRAGLIA, M.; EHLERSG, M.; VAN GENDEREN, J.; JACKSON, D.; LEWIS, A.J.; PESARESI, M.; REMETEY-FÜLÖPP, G; SIMPSON, R.; SKIDMORE, A.; WANG, C.; WOODGATE, P. Nextgeneration Digital Earth. Proceedings of the National Academy of Sciences of the United States of America, 109 (28), 11088-11094, 2012.

GOOGLE. Source for elevation data. Google Product Forums. 2008. Available at: https:/groups.google.com/forum/?fromgroups=\#!topic/earthdata/KsRTsXULRNk. Accessed: 20 March 2013.

. Accuracy of Google Earth data satellites. Google Product Forums. 2009. Available at: http://productforums.google.com/forum/\#!category-topic/maps/ maps-water-cooler-off-topic-forum/2qQF6eteanQ. Accessed: 20 March 2013.

Google Earth downloaded more than one billion times. Google Official Blog, 2011. Available at: http://googleblog.blogspot.mx/2011/10/google-earthdownloaded-more-than-one.html. Accessed: 18 March 2013.

. Building a better map of Europe. Google Official Blog, 2012. Available at: http://googleblog.blogspot.com/2012/12/building-better-map-of-europe.html. Accessed: 26 March 2013.

Imagery sources. Google Earth Policies, 2013a. Available at: http://support.google.com/earth/bin/answer.py?hl=en\&answer=21413. Accessed: 20 March 2013. 
Google Earth Projection. Google Earth Help. 2013b. Available at: https://support.google.com/earth/answer/148110?hl=en. Accessed: 18 July 2013.

INEGI. INSTITUTO NACIONAL DE ESTADÍSTICA Y GEOGRAFÍA (MÉXICO). Catastro de la Propiedad Social. 2013. Available at: http://www.inegi.org.mx/geo/contenidos/catastro/presentacionpropiedadsocial. aspx. Accessed: 22 March 2013.

NOWAK, D.J.; GREENFIELD, E.J. Evaluating the national land cover database tree canopy and impervious cover estimates across the conterminous United States: A comparison with photo-interpreted estimates. Environmental Management, 46, 378-390, 2010.

PERISSIN, D.; WANG, Z.; LIN, H. Shanghai subway tunnels and highways monitoring through Cosmo-SkyMed Persistent Scatterers. ISPRS Journal of Photogrammetry and Remote Sensing, 73, 58-67, 2012.

POTERE, D. Horizontal positional accuracy of Google Earth's high-resolution imagery archive. Sensors, 8, 7973-7981, 2008.

PERUCCACCI, S.; BRUNETTI, M.T.; LUCIANI, S.; VENNARI, C.; GUZZETTI, F. Lithological and seasonal control on rainfall thresholds for the possible initiation of landslides in central Italy. Geomorphology, 139-140, 79-90, 2012.

RAN. REGISTRO AGRARIO NACIONAL. Normas técnicas para la delimitación de las tierras al interior del ejido. Diario Oficial de la Federación, México. 1995.

SALINAS-CASTILLO, W.E.; PAREDES-HERNANDEZ, C.U. Horizontal and vertical accuracy of Google Earth ${ }^{\circledR}$ : Comment on "Positional accuracy of the Google Earth terrain model derived from stratigraphic unconformities in the Big Bend region, Texas, USA" by S.C. Benker, R.P. Langford and T.L. Pavlis. Geocarto International, In Press. DOI:10.1080/10106049.2013.821176

TUCKER, C.J.; GRANT, D.M.; DYKSTRA, J.D. NASA's Global Orthorectified Landsat Data Set. Photogrammetric Engineering \& Remote Sensing, 70(3), 313-322, 2004.

WHEATON, J.M.; GARRARD, C.; WHITEHEAD, K.; VOLK, C.J. A simple, interactive GIS tool for transforming assumed total station surveys to real world coordinates - the CHaMP transformation tool. Computers \& Geosciences, 42, 28-36, 2012.

YOUSEFZADEH, M.; MOJARADI, B. Combined rigorous-generic direct orthorectification procedure for IRS-p6 sensors. ISPRS Journal of Photogrammetry and Remote Sensing, 74, 122-132, 2012.

YU, L.; GONG, P. Google Earth as a virtual globe tool for Earth science applications at the global scale: progress and perspectives. International Journal of Remote Sensing, 33(12), 3966-3986, 2012.

(Recebido em abril de 2013. Aceito em setembro de 2013). 